\title{
COMMONS $n^{\circ} 3$
}

COMMONS - Revista de Comunicación y Ciudadanía Digital

Publicación bianual

Volumen 2, Número 3

ISSN 2255-3401

Noviembre 2013

NUEVAS HERRAMIENTAS PARA VIEJOS INTERROGANTES. CONTRADICCIONES DE LA COMUNICACIÓN DE LAS ORGANIZACIONES DE DESARROLLO EN LA ERA DE LA SOLIDARIDAD DIGITAL

María José Lucerga

Fecha de envio: 30/09/2013

Fecha de aprobación: 31/10/2013 


\section{NUEVAS HERRAMIENTAS PARA VIEJOS INTERROGANTES. Contradicciones de la comunicación de las organizaciones de desarrollo en la era de la solidaridad digital.}

\section{LATEST TOOLS FOR OLD CHALLENGES. Ngos communication contra- dictions in the in the digital era.}

María José Lucerga

\begin{abstract}
Resumen
La comunicación de las organizaciones de desarrollo se ha caracterizado durante las últimas décadas por la adopción de un modelo esencialmente mediático y publicitario, que apostaba por la construcción de la identidad de las ONGD en términos de lovemark y proponía una relación con los destinatarios basada en la identificación entre estos y la marca solidaria.

El debilitamiento del Tercer sector, agravado por la crisis, y la consolidación del paradigma de la pancomunicación han agudizado las contradicciones derivadas de este modelo, al tiempo que parecen abrir nuevas vías para superarlo. Tomando como referentes algunas de las últimas actuaciones desarrolladas en la red y en eventos culturales por conocidas ONG y ONGD, en este artículo reflexionamos acerca de la capacidad del nuevo universo digital para resolver esas contradicciones y para desarrollar una comunicación solidaria que fomente realmente la interacción participativa, crítica y transformadora entre las organizaciones y los ciudadanos.
\end{abstract}

\section{Palabras clave}

comunicación solidaria, redes sociales, educación para el desarrollo, ONGD, sociedad digital.

\begin{abstract}
Over the last decades, the communication of development organizations (NGOs) has essentially been characterized by the adoption of an advertising and media model. This model was in favour of the creation of the organizations' identity in terms of lovemark proposing a relationship with the citizens based on the identificacion between them and the supportive brand.

The weakening of the Voluntary Sector, aggravated by the crisis, and the consolidation of the pancommunication model have sharpened the contradictions arising from this model, while it seems to open new roads to overcome it. Taking as a reference some of the most recent actions developed on the Internet and in well-known NGOs and Development NGOs cultural events, in this article we focus on the capacity of the new digital universe to solve these contradictions, and to develop a solidarity communication which actually promotes the participatory, critical and transforming interaction between organizations and citizens.
\end{abstract}

Keywords

communication for solidarity, social network, NGOs, education for development, digital society. 
que levantaban las paredes de ese nuevo mundo mediante sus proyectos de cooperación y los cauces que nos permitían participar en su construcción a través de la aportación económica, el voluntariado o las actuaciones en el campo de la educación.

Esta visibilidad fue el resultado de décadas de duro trabajo pero también de una intensa labor en el campo de la comunicación mediática que, al tiempo que las convertía en referentes, hacía aflorar las contradicciones que han marcado el debate sobre estas organizaciones en los últimos tiempos (Burgui 2012; Erro 2012; Lucerga, 2005; Martínez, 2011; Nieto, 2002; Nos, 2007; Nos y Benet, 2003).

Y en esa reflexión andábamos cuando nuevos factores entraron en escena. El primero de ellos ha sido una crisis que ha puesto patas arriba nuestra idea de progreso y nuestra autoimagen de nuevos ricos; el segundo, una eclosión del paradigma de la pancomunicación, encarnado en el ámbito de lo tangible en ese objeto capaz de convertirnos en cyborgs (el ¿teléfono? móvil) y en lo intangible en la arquitectura de las redes sociales. Para complicar aún más el panorama, todo ello ha ido acompañado de un proceso de pérdida del protagonismo de las ONGD en el imaginario de la lucha social debido al surgimiento de otros actores que parecen haber conectado mejor con el descontento y las preocupaciones de los ciudadanos (movimiento 15M, Democracia Real Ya, Plataforma Antidesahucios...).

En estas páginas nos preguntamos hasta qué punto el nuevo marco que acabamos de exponer -en el especial la extensión de la cultura digital- está abriendo la puerta realmente a un modelo de comunicación diferente que ayude a resolver las contradicciones a las que hacíamos alusión. Para ello nos serviremos de algunas de las actuaciones llevadas a cabo en la red y en eventos culturales por ONG y ONGD como Save the Children ("Toy Sessions"), Intermón Oxfam ("Caza al banquero en el Low Cost Festival" y "\#Yo vigilo"), Acción contra el Hambre ("Generación No Hunger") o Ayuda en Acción ("Reality sin show"). A excepción de la última, que se puso en marcha en 2008, todas las demás se han desarrollado durante el verano de 2013.

Desde nuestro punto de vista, los retos a los que se enfrentan las organizaciones de desarrollo a la hora de comunicarse en estos escenarios y, por consiguiente, las preguntas que debemos hacernos no han variado en lo sustancial: ¿cómo conciliamos las necesidades -ahora más acuciantes- de viabilidad económica con la independencia con respecto al Estado y al mercado?, ¿cómo compaginamos la atención a emergencias con la difusión de la labor a largo plazo sin que lo que se comunica en ambos casos acabe siendo 
1.- Para Nos (2007), la "eficacia cultural", en el caso de la comunicación de las organizaciones de desarrollo, es inseparable del ejercicio de una serie de responsabilidades discursivas coherentes con su identidad. Tomando como referencia la aportación de Iniciativa Social y Estado del Bienestar (2006), la autora habla de fomento del desarrollo de una mayor solidaridad colectiva, dinamización del tejido social, contribución a la constitución de una sociedad civil más fuerte y activa, creación de redes de solidaridad y lucha contra los efectos negativos de la acción del Mercado y el Estado. La eficacia comunicativa, entendida en términos de "eficacia cultural", debe ser al mismo tiempo "eficacia educativa" (que ejerza una influencia positiva en términos de responsabilidad y solidaridad sobre las ideas, valores y conductas de los ciudadanos y ciudadanas), simbólica (que detecte situaciones de violencia cultural y promueva una cultura de paz) y transformadora (que genere una interacción social realmente productiva). incoherente?, ¿cómo construimos y transmitimos una identidad clara frente a otros emisores pretendidamente solidarios con mayor capacidad para hacerse visibles y para investirse con los valores de las ONGD?, ¿cómo podemos utilizar la comunicación como herramienta educativa en el contexto de la sociedad del espectáculo?, ¿cómo dejamos de interactuar con públicos para pasar a hacerlo con ciudadanos?, ¿cómo pasamos de la dinámica unidireccional emisión-recepción a una comunicación que implique participación cooperativa en la construcción de los mensajes? Y ante todo, ¿cómo aseguramos que esa participación sea significativa, crítica y transformadora?, ¿cómo compartimos un discurso de denuncia y transformación radical con una ciudadanía que ya no está tan dispuesta a escucharlo porque tampoco está ya tan segura de ser primer mundo y desea una salida del túnel de la crisis que le permita volver a afirmarse como tal? Es más, ¿el problema es que no sabemos comunicarlo o que hemos acabado creyéndonos eso de los fallos de funcionamiento del capitalismo y la falta de control del sistema, relegando lo de "Otro mundo es posible" a mero eslogan afortunado?

Como ya hemos indicado, es cierto que las nuevas tecnologías tienen una capacidad de penetración que no ha tenido ningún otro medio, y que nos ofrecen la posibilidad de interactuar con los ciudadanos de forma constante e individualizada, permitiendo a los usuarios intervenir en el contenido y convirtiéndolos en actores (Burgui, 2012). Pero también lo es el hecho de que cada vez están más imbuidas por la lógica mercantil y espectacular y que tener una vía abierta de comunicación no significa que lo que comunicas sea coherente con lo que eres ni garantiza su eficacia cultural en los términos que establece Nos $(2007)^{1}$. Por eso, la respuesta a estos interrogantes, especialmente a los tres últimos, debe ser el sustento de cualquier acción comunicativa de una organización de desarrollo y toda reflexión sobre la comunicación de las ONGD debe ser al mismo tiempo una reflexión sobre la identidad de un sector que nunca ha sido tan sólido como podía parecerlo en sus momentos de máxima visibilidad mediática.

\section{¿Un gigante con pies de barro?}

La vulnerabilidad ha sido una característica del denominado Tercer Sector español desde su propio nacimiento. En el año 2002, García Inda mencionaba dos tendencias ligadas a su crecimiento: la fragmentación y la escasa correspondencia entre el número de asociaciones y su integración real en el tejido social. 
Con respecto a la segunda, los datos procedentes del último informe CONG$\mathrm{DE}^{2}$ reflejan una base social de 2.600 .000 personas y entidades socias, donantes y voluntarias. De toda esta cifra, el número de voluntarios asciende a $14.000^{3}$, es decir, la amplia mayoría de esa base está compuesta por donantes. Sin embargo, una donación (sea esporádica o estable) no refleja hasta qué punto uno comparte los análisis y las propuestas de transformación de una ONGD, como tampoco lo reflejan esas conductas menos comprometidas que Carlos Ballesteros (2002) reúne bajo el paraguas de "solidaridad del ratón". Nos referimos a esos sms, whatsapp o "me gusta" de Facebook tan presentes en las nuevas acciones de comunicación de las ONGD en el universo digital y que, como nos recuerda una reciente campaña de recaudación de fondos de Unicef Suecia ${ }^{4}$, tan inútiles resultan para salvar vidas y probablemente para cambiar algo.

Por lo que respecta a la fragmentación, Pérez y Navarro (2013) indican que el TSAS recoge un número aproximado de 29.700 entidades, con fines, filosofías, visiones y tamaños diferentes. Incluso dentro de la CONGDE nos encontramos con diversidad de tamaños (desde los 250 trabajadores de las grandes organizaciones, que representaban tan solo el $8 \%$ de la Coordinadora en el año 2010, hasta los 10 de ese 20\% de pequeñas ONGD), de formas jurídicas (con predominio creciente de las fundaciones, un 54,3\% en 2010) y de proyectos de actuación. Pero los ciudadanos, poco familiarizados con las generaciones de Korten o con las nuevas generaciones emergentes de ONG subsidiaria, instrumental, de oportunidad o altermundialista de las que habla Gómez Gil (2005), son incapaces de distinguir no ya solo entre una ONGD y otras organizaciones solidarias, sino entre estas y las fundaciones puestas en marcha por instituciones y empresas que en el mejor de los casos se creen lo de la Responsabilidad Social Corporativa y en el peor han descubierto las ventajas fiscales y de imagen de la acción "solidaria".

Junto a estos dos condicionantes, la financiación se convierte en el tercer eje de la fragilidad de las ONGD. Los fondos que permiten la existencia de las organizaciones solidarias tienen dos procedencias: pública (a través de subvenciones comunitarias, estatales, autonómicas y locales) y privada (donaciones de empresas y particulares). Tradicionalmente, cada una de ellas ha llevado consigo un tipo de servidumbre. En el caso de las públicas, el miedo a su desaparición si uno es demasiado crítico con las políticas de los gobiernos; en el de las privadas, la conversión de la captación de fondos en una prioridad comunicativa. Esto implica habitualmente el sacrificio de la profundidad de los mensajes para llegar a un público más amplio, la asunción de los cánones de la comunicación mediática como los más eficaces, la
2.- A la espera de que estén disponibles en la web de la CONGDE los datos globales del Informe 2012, ofrecemos los de 2010, recogidos en el Informe de la Coordinadora sobre el sector de las ONDG 2011. Al final del artículo se indican las referencias completas de la publicación.

3.- A partir de los datos de 2010, Pérez y Navarro (2013) aportan las cifras de 635.961 personas asalariadas (que representaban el 3,5\% del mercado de trabajo nacional según la EPA del IV trimestre de 2010) y de casi 1,1 millones de voluntarios para el conjunto del Tercer Sector de Acción Social (TSAS) español.

4.- Disponible en http:// www. youtube.com/ watch?v=i5UIImW1s4w. Consultado el 25 de agosto de 2013. 
5.- Según datos ofrecidos por Monserrat (2013), el análisis del presupuesto de gastos consolidado de las Comunidades Autónomas en el "Programa de Servicios sociales y Promoción Social" para el periodo 2008-2012 refleja un crecimiento del gasto del $16,72 \%$. Sin embargo, el aumento real solo se corresponde con los dos primeros años, ya que a lo largo de 2011 y 2012 se produjo un descenso de un $3,65 \%$. pérdida de radicalidad en la denuncia de las prácticas empresariales o la aceptación acrítica de estrategias de colaboración que acaban siendo más rentables para las empresas. Algunas de las ONGD que han defendido a capa y espada la independencia de los fondos públicos han acabado siendo las abanderadas de este proceso de asunción inconsciente de las pautas de comunicación de la sociedad de mercado.

Este paisaje, ya de por sí complicado, se ha oscurecido más en estos últimos tres años. Los datos que recoge el Informe 2011 de la CONGDE reflejan que el 58\% de sus fondos procedía en 2010 del sector público. Eran los años del gobierno de José Luis Rodríguez Zapatero, y en ese mismo informe se destacaba el crecimiento sostenido del dinero dedicado por el Estado a la cooperación entre 2006 y 2010 5 . A pesar de sus fugaces efectos positivos, este aumento de recursos trajo otras consecuencias que acabaron afectando a la independencia y el estilo de trabajo de las ONGD. Martínez (2011) destaca algunas de ellas:

- Definición de los proyectos en función de lo que las convocatorias de ayuda considerasen "financiable".

- Adaptación de la estructura de las organizaciones a las crecientes exigencias técnicas y burocráticas, con incremento de la organización, profesionalización y formación técnica.

- Crecimiento del número de ONG (sobre todo las pertenecientes a la categoría "oportunista").

- Mayor competencia y necesidad de diferenciación a través del marketing y la comunicación, junto con el proceso contrario de creciente indistinción entre lo que son ONGD y lo que no lo son.

- Descenso de la independencia a la hora de la denuncia.

Para Martínez (2011), esta situación se tradujo en un aumento de actuaciones pero no de la capacidad transformadora de las ONGD, y en un debilitamiento de su relación con la ciudadanía más activa y comprometida, que se ha mostrado crítica con la burocratización y la asepsia de algunos discursos. Mientras las ONGD crecían en número y en visibilidad, convertidas en las grandes gestoras de las políticas de cooperación para el desarrollo, disminuía su base social y su capacidad para realizar análisis y propuestas globales de cambio.

El informe de la CONGDE que estamos manejando ya nos avisa de lo que estaba por llegar, cuando comenta que el incremento de la ayuda estatal se había visto acompañado de un alarmante descenso de las subvenciones por 
parte de las administraciones autonómicas y locales, y dejaba constancia de los impagos. Tres años después, el problema más acuciante ya no radica en cómo gestionar la aportación pública sin perder radicalidad o identidad sino en cómo sobrevivir a los brutales recortes que ha sufrido la cooperación al desarrollo desde el inicio de la crisis.

En noviembre del año pasado, eldiario.es ${ }^{6}$ recogía la bajada de un $70 \%$ del presupuesto de cooperación desde 2010 y la reducción de 300 millones de euros contemplada en los presupuestos de 2013, indicando que la nueva cifra de cooperación al desarrollo española se situaba en un $0,2 \%$ de la Renta Nacional Bruta, lejos de la histórica reivindicación del 0,7\%. Si nos vamos a cifras más actualizadas, la web de la plataforma $2015 y m a ́ s^{7}$ recoge un recorte de un $49,7 \%$ solo en 2012 y un porcentaje de un $0,15 \%$ de la RNB dedicado a cooperación, lo que nos sitúa en términos relativos en el puesto 21 de los 24 países que integran el CAD.

Los efectos de estas políticas sobre las organizaciones solidarias han sido devastadores. Todos podemos mencionar casos de pequeños proyectos que han desaparecido, dejando desprotegidos a sus beneficiarios y con una importante deuda a las organizaciones e incluso a las personas concretas que los sustentaban. Pero la crisis también ha llegado a los grandes. Según datos recogidos por la edición digital del diario Expansión en julio de $2012^{8}$, Intermón-Oxfam se vio obligada en marzo de ese año a presentar un ERE que supuso el despido de casi una quinta parte de sus trabajadores en España ${ }^{9}$. Igualmente, Cruz Roja vio venirse abajo algunos de sus proyectos y tuvo que reducir la plantilla. Un caso aparte lo representa Médicos sin Fronteras. Entre 2009 y 2010 se incrementó su número de socios, aumentando su aportación privada y compensando así el descenso de lo público. En su memoria de 2012, esta organización señala que el 92\% de sus fondos son de procedencia privada y aunque destacan una caída de las donaciones espontáneas, el número de socios ha vuelto a crecer un 5,4\%, alcanzando los 300.000.

Como señalábamos anteriormente, organizaciones como Médicos sin Fronteras ven en la financiación privada la garantía de su independencia económica y de acción. Pero a nadie se le oculta que funcionar prioritariamente con las aportaciones de los socios implica la necesidad de captarlos y fidelizarlos y que eso se traduce en otro tipo de dependencia. Dado que la reducción de la ayuda estatal aboca a las organizaciones a potenciar la vía privada, son las contradicciones que se derivan de ella las que más van a afectar a la comunicación de las organizaciones solidarias de aquí en adelante.
6.- $\quad$ http://www.eldiario. es/sociedad/cooperacionpresupuesto-recortesONG 064743716. html. Consultado el 10 de agosto de 2013.

7.http://2015ymas. org/comunicacion/ com un ic ados/ opinamos/2013/308/ espana-lidera-la-reduccionde-la-ayuda-oficial-aldesarrollo-y-Ileva-Iacifra-de-cooperacion-asu-minimo-historico/\#. UgPVY9LwnIM. Consultado el 10 de agosto de 2013

8.- http://www.expansion. com/2012/07/21/ economia/1342864966. $\underline{\mathrm{html}}$. Consultado el $10 \mathrm{de}$ agosto de 2013.

9.- En su web (consultada el 25 de agosto de 2013) se habla de "reducción de costes internos" concretada en la reducción temporal de un $10 \%$ de la jornada de su plantilla en España. 


\section{Las contradicciones de la comunicación solidaria en la sociedad me- diática, digital y de mercado.}

Para abordar las contradicciones a las que hacíamos alusión en el último párrafo del apartado anterior hemos seleccionado cinco actuaciones de cinco conocidas organizaciones solidarias. Las describimos brevemente:

\section{1.- REALITY SIN SHOW}

En el año 2008, Ayuda en Acción presentó una iniciativa que se canalizó de forma prioritaria a través de Internet y que aprovechaba el tirón del formato televisivo del "reality show", especialmente entre los jóvenes, para concienciar sobre la situación de los países desfavorecidos y para dar a conocer su trabajo. Con la ayuda de prescriptores famosos como los miembros del equipo de Muchachada Nui o Flipi (El Hormiguero), que participaron en los spots de difusión, la organización lanzaba en la red un concurso de propuestas para difundir la realidad de San Juan de Lurigancho, una población peruana donde se había desarrollado uno de sus proyectos. Los autores de las tres propuestas más votadas, elegidas entre las diez finalistas que seleccionaron los internautas, viajaron a la población y convivieron durante 14 días con sus habitantes (de ahí lo del "reality sin show"), convirtiendo su experiencia en un audiovisual destinado a sensibilizar a la población española. La iniciativa contó con la colaboración de Trina y de M80.

\section{2.- GENERACIÓN NO HUNGER}

Se trata de un proyecto de Acción contra el Hambre financiado por la AECID, con el apoyo de Radio 3 como medio oficial. Se centra en la acción cultural y está dirigido, como casi todas estas iniciativas, a un público joven, el de la "primera generación capaz de acabar con el hambre". El uso del inglés, el concepto de generación, la difusión a través de la web y las redes sociales y el centro de interés en producciones culturales como el cómic, el vídeo o el rap están pensados claramente para este segmento de población. Al igual que en el caso de "Reality sin show", el formato es el de un concurso con unos portavoces ganadores y el premio un viaje a Guatemala con el objetivo de realizar un audiovisual colectivo "que ponga en marcha a la Generación No Hunger y genere soluciones para la injusticia que supone el hambre".

$\mathrm{Al}$ entrar en www.generacionnohunger.org, la página del concurso, nos encontramos en primer lugar con un mapa que refleja las cifras del hambre y 
que, cuando se convierte en "mapa del arte", nos muestra los talleres realizados en diferentes países, de la mano de sus coordinadores y sus participantes. Haciendo clic sobre una zona concreta, accedemos a una breve información sobre su situación, un pequeño documental del taller y los resultados del mismo. Por ejemplo, si nos adentramos en Territorio Palestino ocupado descubrimos el taller que Pere Mejan organizó allí con un grupo de chavales y chavalas en enero de 2011. Además de este ha habido talleres de danza, vídeo, rap, muralismo, teatro, cuentos y fotografía.

El concurso consistía en elegir una de estas modalidades y crear una pieza en la que se reflexionase sobre el hambre, sus causas, sus consecuencias y posibles soluciones. Todos los trabajos pueden verse en http://www.generacionnohunger.org/index.php/oir. De ahí han salido recientemente los tres portavoces que han viajado a Guatemala para ampliar su visión del problema y participar en la creación de ese audiovisual colectivo. En la página también se ofrece la opción de firmar y difundir un manifiesto de la "Generación No Hunger".

\section{3.- TOY SESSIONS}

Esta acción de Save the Children ha reunido a un amplio número de músicos que han grabado uno de sus temas con instrumentos de juguete, bien en sesiones de estudio, bien aprovechando el marco de festivales como el FIB, Festimad o Sol Festival. Estas grabaciones se están difundiendo a través de Youtube, de las redes sociales y de http://toysessions.savethechildren.es con el objetivo de concienciar sobre la situación de la infancia en el mundo. En septiembre se va a grabar una canción con todos los músicos participantes. Las posibilidades de colaboración para los ciudadanos pasan por hacerse socio de la organización, realizar una donación puntual, enviar un sms cuyo valor se destina a la alimentación de un niño durante un día o compartir en las redes. El dinero recaudado se destinará a la campaña "Todos contamos". En la sección "cumpledeseos" puedes asociar tu donación a objetos concretos como una báscula peso. Asimismo se ofrece la oportunidad de participar en sorteos como el de las guitarras de Alpha Blondy, Manolo García o Melendi.

\section{4.- CAZA AL BANQUERO EN EL LOW COST FESTIVAL}

Nuevamente ligada a los festivales de música, esta iniciativa de Intermón Oxfam se relaciona con la Tasa Robin Hood y se centra en una acción de 
recogida de firmas para que esta se aplique. Se ha desarrollado durante la celebración del Low Cost Festival, a finales de julio de 2013, con la idea de extenderse a otros festivales. En ella se utilizaba la figura del banquero oscuro como encarnación de todos los males de la economía especulativa, y se pedía a los asistentes al festival que lo cazasen, es decir, que lo localizasen y que tuiteasen a través de una app para smartphone las diferentes frases que este personaje lucía en su maletín. Entre todos los mensajes enviados se realizó un sorteo que daba opción al uso exclusivo de un WC durante los días del festival y permitía el acceso a la zona VIP.

\section{5.- \# YO VIGILO}

Es una campaña de recogida de firmas de Intermón Oxfam para presionar a los congresistas durante el verano de cara a la aprobación de los presupuestos generales del Estado para el año 2014. Consiste en hacerse una fotografía en actitud vigilante y tuitearla para que llegue como firma a nuestros representantes. Se ha difundido fundamentalmente a través de las redes sociales.

Estamos hablando de campañas que comparten un destinatario común (los jóvenes) y el uso de las nuevas tecnologías como herramienta de actuación. En cuanto a sus objetivos, son acciones destinadas a la recogida de firmas para una acción concreta (las dos de Intermón Oxfam), recaudación de fondos (la de Save the Children) y sensibilización al mismo tiempo que se da a conocer la labor de la organización (Ayuda en Acción y Acción contra el Hambre). El objetivo final de la sensibilización está implícito en todas ellas. La cuestión que nos interesa es si el mensaje que transmiten estas actuaciones es coherente con ese objetivo y si el uso de las herramientas digitales garantiza por sí mismo, más allá de las ventajas de la inmediatez, la penetración y la interactividad, una participación crítica y transformadora en estos procesos de comunicación.

Nuestra selección no se ha guiado por criterios de exhaustividad sino de representatividad. Por su tamaño, volumen de socios, atención prestada a la comunicación y presencia en los medios, estas cinco organizaciones gozan de un amplio grado de conocimiento y reconocimiento social, por lo que podemos considerar sus actuaciones como un termómetro que marca la tendencia del conjunto del sector. Por otra parte, su visibilidad mediática hace que muchos ciudadanos identifiquen sus acciones con el comportamiento de todas las demás. 
Proponemos un acercamiento de tipo cualitativo, que toma como referencia metodológica el análisis del discurso centrando nuestra atención en el grado de coherencia del contenido de los mensajes con la identidad comunicativa de los emisores y en el reflejo en la construcción de los mismos de un destinatario modelo que se corresponde con el usuario de las nuevas herramientas de la sociedad digital.

Nos detenemos primero en las contradicciones relacionadas con la comunicación mediática y su presencia en los mensajes seleccionados.

\section{La pervivencia de la lógica mediática en la comunicación solidaria digital}

Desde el momento en que las ONG y ONGD se plantearon la necesidad de hacer llegar a la sociedad su trabajo y sus mensajes, optaron por asumir la cuestión de la comunicación en términos predominantemente mediáticos, centrando una buena parte de sus esfuerzos en hacerse presentes en los medios de masas (y cada vez más en Internet y en las redes sociales). Dichos medios representaban la única posibilidad de hacerse ver y escuchar en unas sociedades cada vez más complejas y con menos opciones de comunicación cara a cara. Erro (2012) habla de una mirada mediocentrista e instrumental que, aunque convive actualmente con otra más compleja y rica, sigue siendo hegemónica. Esta mirada parece olvidar que todo lo que una organización es y hace comunica, que comunicación y educación van indisolublemente unidas y no pueden transmitir mensajes contradictorios, que una comunicación transformadora integra los conceptos de información y persuasión en una dinámica interactiva en la que organizaciones y ciudadanos cooperan en la construcción de los mensajes y que "esta comunicación participativa necesita como condición previa ofrecer los elementos para interpretar el contexto y, por consiguiente, para poder identificar las raíces de las crisis o conflictos" (Burgui, 2012: 190), algo que en teoría debería ser más sencillo en la nueva cultura digital.

Los datos del Informe de la CONGDE Así nos ven 2010. Qué sabemos y qué valoramos de las ONGD confirman esa hegemonía ya que los medios convencionales siguen siendo los principales canales para recibir información sobre las ONGD, sus actuaciones y los países donde trabajan, con un 29,7\% para la televisión, un $15,5 \%$ la prensa escrita y un $8,3 \%$ la radio. Internet es usado por el 7,4\%, mostrando una tendencia creciente con respecto a años anteriores. Curiosamente, los propios periodistas consideran otros medios 
10.- El informe Perfil sociodemográfico de los internautas. Análisis datos INE 2012, realizado por el ONTSI, indica que el perfil con mayor porcentaje de internautas $(98,4 \%)$ corresponde a personas con la primera etapa de educación secundaria con edad entre 16 y 24 años y que residen en municipios de más de 50.000 habitantes. A partir de los 54 años se produce un descenso significativo.

11.- La concepción de la comunicación como interacción se encuentra presente ya, entre otros, en los trabajos de Bajtin (1985) o en la teoría de la Enunciación de Benvéniste (1977). Asimismo, es la base de la psicología social de G.H. Mead (1982), de la corriente de la Pragmática de la comunicación humana (Watzlawick, Jackson y Beavin 1986), de los trabajos de Bateson y la Escuela de Palo Alto en el ámbito de la psiquiatría social (Bateson y Ruesch 1984; Bateson 1985; 1993) o de la sociología de Ervin Goffmann (1979; 1987). de información más eficaces cuando los receptores son ellos mismos. En las conclusiones del Encuentro Los medios de comunicación y las ONGD. Situación actual y retos 2007, los viajes al terreno (84\%), informes (79\%) y ruedas y notas de prensa (52 y $42 \%$ respectivamente) se situaban por encima de los audiovisuales y el material gráfico (26 y 21\%).

En realidad, la crisis ha reducido la presencia de las organizaciones solidarias en los medios convencionales (salvo fechas señaladas o situaciones de emergencia) y estas han volcado su presencia en la red, a través de sus webs, portales como Youtube o las redes sociales. La elección de estos nuevos canales conlleva un notable descenso de los costes de producción de los mensajes, una mayor capacidad de acercarse a los ciudadanos de forma personalizada y, presumiblemente, una posibilidad de interacción real y constructiva entre emisores y receptores. Pero también selecciona el tipo de público al que realmente llegamos ${ }^{10}$.

Trabajos como el de Scolari (2008) o Silva (2005; Aparici y Silva, 2012) exponen las bases del modelo de comunicación digital y reflexionan sobre la nueva concepción de emisor, receptor, mensaje y relación interlocutiva que se deriva de él, destacando tres conceptos básicos: interactividad, hipertexto e hipermediación.

La noción de interactividad implica la visión de la comunicación como cooperación y la concepción de la relación interlocutiva como expresión y confrontación de identidades. Los roles de emisor y receptor se diluyen, ya que el receptor tiene la posibilidad de intervenir de forma activa en la construcción de los mensajes, pasando de espectador a actor. En realidad, lo novedoso de este planteamiento no estriba en la idea de interacción ${ }^{11}$, sino en el trasvase de las características de la comunicación interpersonal cara a cara a las relaciones entre organizaciones/instituciones/empresas e individuos y en la superación de los límites espacio-temporales.

El concepto de "hipertexto" a su vez tiene relación con otros precedentes como el de "obra abierta" de Eco (1985), el de "intertextualidad" (Kristeva 1967; Genette, 1989) o con corrientes de teoría literaria como la Estética de la recepción, que reivindican la obra como un conjunto de posibilidades interpretativas que solo se actualiza (cada vez de una forma diferente) mediante una labor de clausura de sentido ejercida por un lector-constructor armado de su experiencia, sus conocimientos del lenguaje y del mundo y su intertexto lector (Mendoza, 2012). En el nuevo universo digital, esta apertura potencial del texto analógico se torna literal, los recorridos se multi- 
plican, los centros se vuelven móviles y la posibilidad de cooperación en la construcción del sentido se vuelve exigencia ${ }^{12}$. Asimismo, la lectura intensiva se vuelve extensiva, con los retos que de ello se derivan para los procesos de comprensión y expresión.

Junto a todo ello, el concepto de "hipermediación", heredero del de "mediación" de Martín (1987), supera la visión de la red y las nuevas tecnologías digitales como meras herramientas, para considerarlas un espacio de conflicto donde se construyen identidades personales y sociales y donde se ponen en juego estrategias de dominación y de resistencia. ${ }^{13}$

El análisis de los mensajes de las organizaciones de desarrollo nos muestra que este nuevo escenario que plantea la sociedad digital no necesariamente los libera de las ataduras de la lógica mediática, que se muestran a través de las siguientes características (García, 2002):

- La visibilidad se fundamenta esencialmente en la apariencia. De ahí la necesidad de acciones llamativas, que puedan acabar convertidas en noticia o en un vídeo en Youtube. En el caso de las acciones "\#Yo vigilo" o "Toy sessions", la gente acaba prestando más atención a la fotografía enviada o a las diferentes versiones de los temas de los músicos que a lo que hay detrás.

- La credibilidad está en función de la imagen y de la repetición (o del número de seguidores, me gusta, visitas al portal o enlaces compartidos en las redes sociales).

La injusticia y su contrapunto de solidaridad no son solo una experiencia para comunicar sino algo que hay que experimentar. Por lo tanto, hay que construir acontecimientos que consigan crear sensaciones en el destinatario. Al formato clásico de los telemaratones se unen otros más innovadores como los concursos que ofrecen como premio viajes al terreno que luego se comparten a través de la red. El proyecto "Reality sin show", recordemos, ofrecía a los ganadores del concurso un viaje a San Juan de Lurigancho (Lima) para conocer la realidad de primera mano y darla a conocer después a los demás, en este caso mediante vídeos ${ }^{14}$.

- La realidad presentada, para despertar la atención, debe salirse de lo común o suscitar emociones a través de la pena, el dolor, el recurso a lo desagradable o la imagen de la infancia desvalida. Esta es tal vez la característica que más se ha cuidado desde
12.- Sin embargo, trabajos como el de Arroyo, Baños y Van-Wyck (2013) ponen de manifiesto que estas nuevas posibilidades no siempre se están aprovechando para construir una comunicación acorde con ellas. A partir del análisis de contenido de 370 mensajes de organizaciones del Tercer Sector a través del canal Youtube, estos autores llegan a la conclusión de que la previsibilidad, el carácter informativo, la homogeneidad y la baja creatividad son las características dominantes. Dejando de lado las cuestiones económicas (que, como los autores reconocen, son y de siempre han sido un importante condicionamiento en la comunicación de estas organizaciones), lo cierto es que todavía se está haciendo un uso mayoritario de la red como mero soporte para "colgar" lo mismo que se emitiría en medios analógicos pero con la esperanza de alcanzar una mayor difusión.

13.-Podemos encontrar una visión crítica de esos procesos de construcción de identidad, del mito de la libre circulación de información y de la puesta en marcha de estrategias de dominación en la red en los trabajos del colectivo Ippolita, como los dedicados a Google (2010) o Facebook (2012).

14.- Como el que puede verse en (http://www.youtube. $\mathrm{com} /$ watch? $\mathrm{v}=\mathrm{r} 7 \mathrm{DENOgArgQ}$, Consultado el 26 de agosto de 2013. 
la puesta en marcha del Código de conducta de la CONGDE en 1998 y hoy en día es difícil encontrar en España campañas como las famosas de Anesvad o como la que desató la polémica en el Reino Unido en 2011 con el spot "Unwatchable", de la organización Save the Congo, en el que aparecían imágenes explícitas de violaciones y asesinatos para sensibilizar sobre el terrible trasfondo del negocio de los móviles y sus consecuencias para los habitantes de esta república africana ${ }^{15}$. En general, las últimas campañas intentan mostrar imágenes positivas, que reflejen el destino real de las ayudas y que den mayor protagonismo a los beneficiarios de los proyectos. La campaña de MSF "Ayuda a nacer a Malik" puede ser un buen ejemplo de esta tendencia.

- La aparición en los medios se relega a una información puntual, quedando fragmentada y descontextualizada del mensaje global de la organización. Las redes sociales pueden ser una buena herramienta para paliar este déficit pero, como ya hemos indicado, no debemos olvidar quiénes son sus usuarios ni creer ingenuamente que el cien por cien de los que nos siguen leen a fondo nuestros mensajes, por lo que es bastante fácil que, a veces, los destinatarios se queden en la "cáscara" porque ¿cuántos son los que dan el paso de la lectura en profundidad en un contexto en el que los 140 caracteres de Twitter y los 59 segundos del desaparecido programa de RTVE marcan la pauta de lo que se considera emitible y escuchable o legible? De todas las actuaciones que hemos analizado, creemos que la que mejor resuelve esta cuestión es la de "Generación no Hunger", tanto a través de la información ligada a la presentación de los talleres del "mapa del arte" como mediante los materiales complementarios que se

15.- Puede accederse al spot y a una reflexión sobre la campaña en el blog La regla de William, de José Antonio Ritoré, Disponible en http:// blogs.lainformacion.com/ ladewilliam/2011/10/05/ asesinato-y-violacionen-el-spot-de-una-ong$\%$ C $2 \% B$ Fdonde-esta-ellimite/. Consultado el 18 de agosto de 2013. ofrecen junto con los tutoriales en la sección "Crea y actúa".

- La solidaridad deja de ser una cuestión política para concebirse como un asunto del corazón: la lucha contra la injusticia se reduce muchas veces a una cuestión meramente afectiva e individual y las situaciones de pobreza y marginación no se presentan como fruto de la existencia de conflictos sino como desgracias ocasionales. En general, en los mensajes de las ONGD que aparecen en los medios se sigue echando de menos un análisis de las causas que generan las situaciones de desigualdad. En ocasiones es que no lo hay o lo que se expresa es dema- 
siado simplista. Desde nuestro punto de vista es lo que ocurre con el banquero oscuro de la acción de Intermón Oxfam. Bien es verdad que la banca es una de las bases del capitalismo especulativo, pero cifrar en la figura individual del banquero todas las culpas de la crisis es como pensar que el alfa y la omega del problema de la corrupción están encarnados en la figura del corrupto. Esta estrategia del "chivo expiatorio", utilizada en ciertos discursos reduccionistas de la izquierda actual pero también por movimientos totalitarios de infausto recuerdo, puede ser consoladora en estos momentos de frustración y carencia de alternativas en los que la doctrina del shock de la que hablaba Klein (2007) ha demostrado ser plenamente eficaz, pero fuera del consuelo, la idea de cazar al malvado banquero o meter en la cárcel al que corrompe o al que se deja corromper (por muy necesario y justo que sea) nos acaba distrayendo del problema real. Por un lado, la banca especulativa y depredadora contemporánea y la corrupción no son el resultado de un mal funcionamiento o una falta de supervisión del sistema. Son capitalismo en estado puro; por el otro, cada vez que hemos cambiado de cuenta buscando mayor interés, suscrito un plan de pensiones, mirado las cotizaciones del mercado para ver si nuestras pocas acciones habían generado beneficios sin ni siquiera preguntarnos de dónde salían o pedido un crédito al consumo para comprar ese coche mejor que no necesitábamos hemos contribuido a crear la situación en la que hoy nos encontramos. Nosotros también formamos parte de este entramado, y nuestro modo de vida ayuda a consolidarlo y naturalizarlo.

Esta ausencia de análisis crítico hace más difícil que se produzca una toma de conciencia real $y$, por tanto, resta eficacia a las posibles iniciativas de cambio. Y genera confusión cuando la encontramos en mensajes de emisores que supuestamente representan esas alternativas transformadoras.

- El discurso mediático se elabora según los gustos de la audiencia, evitando de entrada aquellos temas que no vayan a ser bien recibidos. Cuando se interroga a los encuestados en el Informe Cómo nos ven sobre el modo de actuación de las ONGD y a qué deberían dedicarse, las respuestas evidencian una preocupante falta de claridad analítica. Por una parte, la sociedad considera que las acciones de las ONGD deberían ir encamina- 
16.- Un $33 \%$ de los periodistas asistentes al mencionado encuentro Los medios de comunicación y las ONGD. Situación actual y retos 2007, ante la pregunta "Términos con que los medios asocian la información de las ONGD", respondieron "publicitaria". Otras dos respuestas resultan interesantes para la reflexión que estamos llevando a cabo. Un $47 \%$ consideró que la información era "demasiado reiterativa", mientras que un $77 \%$, ante la pregunta de "aspectos mejorables", demandaba más contenidos de interés. Ambas respuestas tienen que ver con el hecho de que los medios consideran la novedad como un componente esencial de lo noticiable. Desafortunadamente, las situaciones que generan la necesidad de ONGD y las causas que las originan no suelen estar muy sujetas a cambios, y la injusticia, por constante, deja de ser noticia a no ser que vaya asociada a alguna catástrofe que venga a empeorar lo ya de por sí terrible. El público se cansa de la visión reiterada de la desgracia, incluso si esta nos toca tan de cerca como la crisis actual.

17.- En el año 2004, Kevin Roberts, alto directivo de Saatchi \& Saatchi, acuñó el término lovemark para referirse a aquellas marcas que, más allá de su dimensión comercial, aspiran a ser un estilo de vida y a establecer con sus clientes una relación casi personal basada en una propuesta de identificación emisor-destinatario. Un desarrollo al completo del concepto se encuentra en Roberts (2005). Prácticamente todas las empresas vinculadas al universo de la comunicación y las nuevas tecnologías están construyendo hoy su comunicación en términos de lovemark. Valga como ejemplo el "Eres lo que escuchas" de la publicidad corporativa de Radio 3. das a paliar y prevenir situaciones relacionadas con "hambre y alimentación" (27,7\%), "salud” (23,4\%) y “educación” (19,2\%) y expone la necesidad de mantener relaciones adecuadas con los países donde se actúa y "desvincular ideológicamente las actuaciones de las ONGD de sus intervenciones" (CONGDE 2010: 33). Al margen del reduccionismo que supone identificar ideología y acción política con la adscripción a uno de los partidos existentes, y del mensaje de inmovilismo que dicha afirmación transmite, lo que pone de manifiesto este informe es que la sociedad que apoya a las ONGD les está pidiendo que renuncien a su dimensión crítica y se limiten "a hacer el bien", como si una cosa no fuera de la mano de la otra. Este no es un problema que afecte solo a las ONGD. Los nuevos colectivos, surgidos como rechazo y alternativa al mundo político oficial, pronto tendrán que vérselas con estas mismas contradicciones ya que la diversidad es una de las principales características de su base social.

En el caso que nos ocupa, la cuestión es si las propias ONGD no están empezando a transmitir este mismo discurso que recoge el Informe, renunciando a una crítica radical del sistema y adoptando en sus mensajes algunas claves propias del capitalismo de mercado.

\section{La marca solidaria}

Las ONGD no solo han entendido hasta hace poco la cuestión de la comunicación prioritariamente en términos mediáticos. Lo mediático se ha considerado asimismo sinónimo de publicitario ${ }^{16}$, y de este modo, se ha empezado a pensar en la identidad de las organizaciones con los parámetros de la identidad de marca concebida como lovemark (Roberts, 2005) ${ }^{17}$ y se ha creído que la eficacia comunicativa pasaba por establecer un proceso de identificación entre esa marca solidaria y los ciudadanos vistos como target. En un trabajo anterior (Lucerga, 2005) analizamos la influencia de este concepto en la comunicación de las grandes organizaciones solidarias tomando como referencia la campaña de Intermón Oxfam "Intermón Oxfam soy IO" y poniendo de manifiesto el peligro de que la asunción del modelo de comunicación implícito en el concepto de lovemark condujese a una indistinción entre la marca solidaria y las marcas comerciales. Tal y como allí se exponía, la confusión resulta a la larga mucho más beneficiosa para las empresas que para las ONGD, porque mientras que para las primeras implica un plus de legitimidad moral para las segundas plantea un problema de percepción 
de su identidad por parte de los destinatarios y de coherencia con el resto de actuaciones llevadas a cabo en los terrenos del análisis, la denuncia y la educación ciudadana.

Junto a esta propuesta de identificación y pertenencia a través de la construcción de un destinatario modelo, que retomaremos en el apartado "Para ti que eres joven", las características de la "comunicación de marca solidaria" se reflejan de este modo en los mensajes analizados:

- Una lógica instrumental, según la cual la gratuidad deja de ser un componente de la acción solidaria. Los emisores solidarios han considerado que los ciudadanos necesitamos un incentivo mayor que nuestra conciencia de la injusticia para escuchar sus mensajes y participar en sus acciones. Se supone que lo que hagamos (la donación, la asistencia a un evento, la firma de un manifiesto o el envío de un mensaje) lo hacemos porque nos ofrecen algo a cambio. Ese algo puede ser un viaje solidario ("Reality sin Show"), la posibilidad de ganar la guitarra de un músico famoso ("Toy Sessions") o una recompensa tan sumamente vital (aunque ciertamente tan demandada en un macrofestival) como un WC privado ("Caza al banquero").

- Exclusividad: entendida en el sentido que apunta Ballesteros (2002), la exclusividad implica la apropiación de la noción de solidaridad por parte de las ONG y ONGD, como si no existiesen otras vías, aunque es evidente que esta afirmación ya no resulta creíble para los ciudadanos. Pero la exclusividad también puede ser entendida en el sentido que la utilizan las grandes marcas, como una diferenciación del colectivo que se identifica con ellas frente a otros colectivos (los premios de la actuación "Caza al banquero en el Low Cost Festival" suponían para los ganadores un privilegio al alcance de unos pocos; además del WC privado te permitían el acceso a la zona VIP).

- Participación indolora: el clic del ratón del que hablaba Ballesteros se ha convertido en una foto, un whatsapp, un me gusta o un comparte. Por ejemplo, mandando la palabra "Sueños" al 28014 puedes colaborar con Save the Children. Es más, parece que toda comunicación solidaria dirigida a jóvenes no solo es indolora, también debe ser lúdica; el reto de capturar la imagen del banquero entre los miles de asistentes a un festival o 
la foto vigilante veraniega del "\#Yo vigilo" se sirven de esa necesidad compulsiva de documentar y retransmitir toda nuestra vida que las redes sociales han entronizado. Los vídeos de las "Toy Sessions" probablemente se compartan más por ver a nuestro cantante favorito tocando un piano de juguete que por lo que de llamada de atención sobre la situación de la infancia tienen. Muchas de estas propuestas corren el peligro de que lo festivo -en alguna ocasión incluso rayano en la frivolidad- diluya el componente de denuncia y reivindicación y, en todo caso, se trata de acciones puntuales que no implican un análisis previo, no requieren compromiso ni garantizan continuidad.

- Empleo de herramientas del capitalismo de consumo, desde la compra (solidaria) hasta el uso de tarjetas, descuentos o planes de pensiones.

- Reclamo de prescriptores famosos (presente en la difusión del "Reality sin show" y alma de las "Toy Sessions", pero también podemos encontrarnos con Lluvia Rojo colaborando en el taller de teatro de la "Generación no Hunger" o en la visita de Gael García Bernal a territorio sirio estos últimos días). En la iniciativa cuentaconmigocontralapobreza.com, la Obra Social de La Caixa ha invitado a numerosos famosos a realizar versiones de cuentos tradicionales, colgándolas en Youtube. Tal vez la más mediática de todas haya sido la protagonizada por Juan Antonio Orenga y los jugadores de la ÑBA, un divertido vídeo sobre un casting para elegir a los siete enanitos del cuento de Blancanieves. Cuando uno ve el vídeo es invitado a hacer un donativo a la entidad que esta, a su vez, hará llegar a Save the Children. Los beneficios económicos los recibe la ONG, pero los de imagen llegan a La Caixa, la gran protagonista. Dudo mucho que los jóvenes sean capaces de distinguir entre esta iniciativa y las anteriores.

\section{Para ti, que eres joven}

Recurriendo de nuevo al Informe 2011, en él se recogen tres perfiles de públicos y de entre ellos se destaca el tercero como uno de los principales. Este público, entre los 18 y los 29 años, valora más positivamente las ONGD y "las empresas privadas". Es decir, es el más proclive a atender el mensaje solidario pero también el menos capaz de analizar las implicaciones del maridaje 
solidario-empresarial y de distinguir una ONGD de otra fundación privada cualquiera. Y este es el destinatario que reflejan los mensajes y actuaciones de las organizaciones solidarias dentro del nuevo universo digital.

En bastantes de las características de este público podemos reconocer rasgos de las iniciativas de comunicación que estamos analizando:

- Sus integrantes poseen estudios secundarios o universitarios.

- Cuentan con un nivel de renta más elevado. Con más de un $50 \%$ de parados jóvenes en este país y con la mayor parte de los que restan subempleados, es evidente que este dato (de 2010) habrá que revisarlo y que esta circunstancia hace que las peticiones de colaboración económica deriven hacia el camino de las aportaciones puntuales mediante envíos de mensajes u otras acciones vinculadas al uso del móvil.

- Diferencian de manera general entre ONG y ONGD.

- Participan en las organizaciones (apoyando económicamente, como voluntariado, asistiendo a actividades, etc.).

- La cultura audiovisual y publicitaria y lo digital forman parte de su "lengua materna", al igual que la música, tanto las descargas como los conciertos en directo, lo que significa que:

- Son más receptivos alaimagen que ala palabra, por lo que se privilegianformatosaudiovisuales (muyexplícitosenelcaso de "Reality sin show", en “\#Yovigilo" o en las "Toy sessions").

- Valoran la novedad constante, el trending topic, la originalidad y los alardes técnicos, porque son estos los que logran imponerse y llamar su atención en un contexto de saturación de estímulos comunicativos. También suelen asociar lo creativo con lo transgresor (Cruces 2001). De ahí que las ONGD estén recurriendo a formatos provenientes de la acción en la calle, los macroconciertos, los eventos y los videojuegos (casi siempre con su continuación, apoyo o reflejo en la red). Tres de las cinco iniciativas analizadas se han desarrollado en el marco de conocidos festivales veraniegos como el FIB, FESTIMAD o Low Cost Festival, y varias de 
ellas han contado con la colaboración de emisoras de radio y productoras musicales. "Toy sessions" tiene a la música como protagonista absoluta y “Generación no Hunger” proponía el rap como una de las modalidades de participación.

- Está más familiarizado con eslóganes y lemas (o con tuits) que con argumentaciones y con la lógica deductiva.

- La globalización cultural parece haberlos convencido de que no hay posibilidad de ser alternativo ni moderno en la lengua vernácula. Por lo tanto, los mensajes de nuestras ONGD hablan de "Generación no Hunger", "Toy sessions" o "Reality sin Show". Los hablantes y sociedades que han vivido situaciones de diglosia conocen bien las consecuencias de negar determinados usos a una lengua. Sin hacer una defensa integrista de la pureza lingüística (aunque no suene muy atractivo, la corrupción y la contaminación son dos de los principales mecanismos que mantienen vivo un idioma), parece que lo que hace unos años imponía la dominación política lo está consiguiendo de una forma indolora pero más efectiva la dominación cultural. Nada nos gustaría menos que ver disminuida por falta de uso la capacidad de nuestra lengua para expresar la solidaridad, y nada nos gustaría más que conseguir que nuestros jóvenes descubrieran las posibilidades de su idioma para construir y expresar su identidad.

- Permanecen prácticamente ajenos a los estímulos que no les llegan a través de los medios y las redes. "Por obvio que resulte, ser joven hoy significa conectarse a distancia, participar en redes sociales, hacerse una identidad virtual, bajarse música y películas, twitear o intercambiar llamadas y mensajes" (Cruces, 2011: 156). A través de estos canales (en realidad, de una concepción restringida de los mismos y del concepto de innovación, como señala Cruces), los jóvenes se socializan de forma mayoritaria y en ellos están construyendo tanto su identidad como su imagen de la marginación, el hambre, la pobreza, la guerra, la tortura y la justicia social.

- Por último, expresan un fuerte rechazo a la política, que identifican con lo institucional, y a todo lo que implique burocratización. Por eso tachan de ideológico (en el sentido reduccionista 
que la derecha ha extendido) cualquier discurso fuerte sobre la injusticia, empezando por la que les afecta a ellos. También por eso han acabado conectando mejor con otros actores sociales que, a su flexibilidad organizativa, han unido una innegable capacidad de expresar el malestar y las ganas de cambio de amplios sectores de la ciudadanía y un eficaz manejo de las herramientas de comunicación propias de la sociedad digital.

\section{Conclusiones}

La identidad de las organizaciones de desarrollo lleva implícita una concepción de la comunicación basada en el establecimiento de un proceso de diálogo capaz de interpelar a los ciudadanos y ciudadanas a nivel individual, a pesar de que los canales sean colectivos. Asimismo, los mensajes deberían reflejar una crítica radical de la injusticia y una invitación a la acción transformadora. Lejos de ser meras herramientas, las nuevas tecnologías nos dibujan un escenario de actuación que, en teoría, facilita la consecución de esos objetivos, eliminando las limitaciones de la comunicación de masas.

Sin embargo, las cinco iniciativas que hemos analizado ponen de manifiesto que la opción por la comunicación digital no implica necesariamente la superación de las contradicciones que han acompañado a la comunicación solidaria dentro de las sociedades de mercado.

En ocasiones observamos en estos emisores solidarios la misma incapacidad que muestra su destinatario modelo para descubrir la presencia de esas contradicciones en unos mensajes que, mientras afirman combatir el sistema, asumen como propias las pautas de comunicación que forman parte de sus entrañas. Así, el diálogo no se plantea entre diferentes que se unen para un fin común sino que se resaltan las ideas de identificación con la organización y pertenencia a un grupo especial. Por otro lado, el miedo a que esa diferencia pueda dificultar la comunicación hace que esta se adapte a lo que creemos que el otro quiere escuchar, asumiendo los cánones de lo espectacular como panacea de la eficacia comunicativa y perdiendo radicalidad en la denuncia. De igual modo, la lógica de la actuación que se promueve suele ir ligada a la espera de una recompensa y la rentabilidad comunicativa se mide con los mismos parámetros que en el ámbito comercial.

También detectamos en estas actuaciones idéntico deslumbramiento por el nuevo universo de las redes, presuponiendo que la capacidad de estar cons- 
tantemente conectado garantiza la interacción productiva y que el hecho de que esta exista implica su carácter transformador.

Para finalizar, nos gustaría indicar que el reconocimiento de estos puntos débiles no quiere decir que no haya elementos esperanzadores en ellas. Con las prevenciones que hemos expuesto a lo largo de estas líneas, creemos que la "Generación no Hunger" contiene pistas que nos colocan en el buen camino.

En esta actuación de Acción contra el Hambre se ofrecen pautas para el análisis del problema de la desnutrición y de las realidades de los países donde la organización está desarrollando sus proyectos, se favorece el conocimiento en directo de esas realidades y el diálogo entre los protagonistas a través del viaje y la difusión tanto de las obras participantes en el concurso como del material que se elabore tras el regreso. Por último, la acción se sostiene en una concepción de participación creativa que requiere de los que intervienen en ella reflexión y actuación.

¿Nos encamina esta dirección a la meta de la eficacia cultural? Desde nuestro punto de vista sí, pero solo si, a la hora de dar respuesta a los dos últimos interrogantes que cerraban nuestra introducción, estas iniciativas dejan claro sin lugar a dudas a través de sus actuaciones y mensajes que la palabra clave del lema "Otro mundo es posible" es "otro". 


\section{Bibliografía}

- $\quad$ APARICI, R. Y SILVA, M. (2012). Pedagogía de la interactividad. Comunicar. Revista científica de Comunicación y Educación, XIX (38), , 51-58.

- $\quad$ ARROYO ALMARAZ, I., BAÑOS GONZÁLEZ, M. Y VAN-WYCK, C. (2013). Análisis de los mensajes audiovisuales del Tercer Sector en YouTube. Revista Latina de Comunicación Social, no 68. Disponible en http://www.revistalatinacs.org/068/paper/980 Madrid/14 Arroyo.html. Consultado el 21 de octubre de 2013.

- BAJTIN, M. (1985). Estética de la creación verbal. México: Siglo XXI.

- BALLESTEROS, C. (2002). Supermercados de la solidaridad. En Nieto, L. (Coord.), La ética de las ONGD y la lógica mercantil (89-135). Barcelona: Icaria.

- BATESON, G. Y RUESCH, J. (1984). Comunicación. La matriz social de la psiquiatría. Barcelona: Paidós.

- BATESON, G. (1985). Pasos hacia una ecología de la mente. Buenos Aires: Carlos Lohlé.

- (1993). Una unidad sagrada. Pasos ulteriores hacia una ecología de la mente. Barcelona: Gedisa.

- BENVÉNISTE, E. (1977). Problemas de Lingüística General II. México: Siglo XXI.

- BURGUI JURÍO, T. (2012). Qué oportunidades ofrece la nueva cultura digital a las ONGD en su condición de entidades educadoras. En Burgui, T. y Erro, J. (Coords.), Comunicando para la solidaridad y la cooperación. Cómo salir de la encrucijada (179-200). Pamplona: Foro Comunicación, Educación y Ciudadanía. Disponible en http://www. iudesp.uji.es/wp-content/uploads/2012/04/teresa-burgui-jurio.pdf. Consultado el 5 de agosto de 2012.

- CONGDE (2007). Los medios de comunicación y las ONGD. Situación actual y retos 2007. Madrid: Publicaciones de la Coordinadora. Disponible en www.congde.org/contenidos/descargar/attachedfiles/962/original?... Consultado el 20 de julio de 2013.

- (2010). Así nos ven 2010. Qué sabemos y qué valoramos de las ONGD. Madrid: Publicaciones Coordinadora. Disponible en http://www.congde.org/contenidos/asi-nos-ven2010-que-sabemos-y-como-valoramos-a-las-ongd.html. Consultado el 3 de agosto de 2013.

- (2011). Informe de la Coordinadora sobre el sector de las ONGD 2011. Madrid: Publicaciones Coordinadora. http://informe2011.coordinadoraongd.org/. Consultado el 20 de 
julio de 2013.

- CRUCES VILLALOBOS, F. (2012). Jóvenes y corrientes culturales emergentes. En García Canclini, N., Cruces, F. y Urteaga Castro Pozo, M. (Coords.), Jóvenes, culturas urbanas y redes digitales (141-157). Barcelona, Ariel.

- ECO, U. (1985). Obra abierta. Barcelona: Ariel.

- ERRO SALA, J. (2012): Comunicación, cooperación internacional para el desarrollo y ONGD: un modelo de trabajo desde la educación y la cultura". En Burgui, T. y Erro, J. (Coords.), Comunicando para la solidaridad y la cooperación. Cómo salir de la encrucijada (137-178). Pamplona, Foro Comunicación, Educación y Ciudadanía. Disponible en http://www.iudesp.uji.es/wp-content/uploads/2012/04/javier-erro-sala.pdf. Consultado el 5 de agosto de 2013.

- GARCÍA INDA, A. (2002). Como mirando por el ojo de una cerradura. En Nieto, L. (Coord.), La ética de las ONGD y la lógica mercantil (59-88). Barcelona: Icaria,

- GENETTE, G. (1989). Palimpsestos. Madrid: Taurus.

- GOFFMAN, E. (1979). Relaciones en público. Madrid: Alianza Universidad.

- (1987). La presentación de la persona en la vida cotidiana. Buenos Aires: Amorrortu.

- Gómez Gil, C. (2005). Las ONG en España. De la apariencia a la realidad. Madrid: Libros de la Catarata.

- IPPOLITA (2010). El lado oscuro de Google. Barcelona: Virus.

- (2012). En el acuario de Facebook. El resistible ascenso del anarco-capitalismo. Madrid: Enclave de Libros.

- KLEIN, N. (2007). La doctrina del shock. El auge del capitalismo del desastre. Barcelona: Paidós Ibérica.

- $\quad$ KRISTEVA, J. (1967). Bakhtine, le mot, le dialogue et le roman. Critique, no 239.

- LUCERGA PÉREZ, M.J. (2005). Cuando IO soy la marca. La solidaridad como construcción publicitaria. Tonos digital. Revista electrónica de estudios filológicos. № 9. Disponible en http://www.um.es/tonosdigital/znum9/estudios/ongtonos.htm.

- MARTÍN BARBERO, J. (1987. Versión revisada 1991). De los medios a las mediaciones. Comunicación, cultura y hegemonía. México: Gustavo Gili. 
- MARTíNEZ OSÉS, P. (2011). Redefiniendo el papel de las ONG: Hacia una mirada más política". En Jornadas Eficacia del desarrollo y ONGDs: Renovando nuestro papel. Madrid, 17 y 18 de mayo de 2011. Disponible en http://www.2015ymas.org/IMG/pdf/ Pablo Martinez Oses.pdf. Consultado el 20 de julio de 2013.

- MEAD, G.H. (1982). Espíritu, persona y sociedad. Barcelona: Paidós.

- MÉDICOS SIN FRONTERAS (2012). Memoria de actividades MSF España 2012. Disponible en www.msf.es/memoria/2012. Consultada el 20 de agosto de 2013.

- MENDOZA FILLOLA, A. coord. (2012). Leer hipertexto. Del marco hipertextual a la formación del lector literario. Barcelona: Octaedro. Colección "Recursos".

- MONSERRAT CODORNIU, J. (2013). El impacto de la crisis en las organizaciones del Tercer Sector. Revista española del Tercer Sector, no 23. Disponible en http://www. fundacionluisvives.org/rets/23/articulos/101402/partes/2.html. Consultado el 21 de octubre de 2013.

- NOS ALDÁS, E. Y BENET, V. J. (2003). La publicidad en el Tercer Sector: tendencias y perspectivas de la comunicación solidaria. Barcelona: Icaria.

- NOS ALDÁS, E. (2007). Lenguaje publicitario y discursos solidarios. Eficacia publicitaria, ¿eficacia cultural'? Barcelona: Icaria.

- PÉREZ IRUELA, M. Y NAVARRO ARDOY, L. (2013). El Tercer Sector de acción social en España. Situación y retos en un contexto de crisis. Revista española del Tercer Sector, no 23. Disponible en http://www.fundacionluisvives.org/rets/23/articulos/101406/ index.html (consultado el 20 de octubre de 2013).

- ROBERTS, K. (2005). Lovemarks. El futuro más allá de las marcas. Madrid: Empresa activa.

- SCOLARI, C. (2008). Hipermediaciones. Elementos para una teoría de la comunicación digital interactiva. Barcelona: Gedisa.

- SILVA, M. (2005). Educación Interactiva: enseñanza y aprendizaje presencial y online. Barcelona: Gedisa.

- URUEÑA, A. coord. (2013). Perfil sociodemográfico de los internautas. Análisis datos INE 2012. Madrid, ONTSI. Disponible en http://www.ontsi.red.es/ontsi/sites/default/ files/perfil sociodemografico del internauta 2012.pdf. Consultado el 29 de agosto de 2013.

- WATZLAWICK, P.,BEAVIN, J.H. Y JACKSON, D. D. (1986). Teoría de la comunicación humana. Barcelona: Herder. 


\section{Biografías}

\section{María José Lucerga Pérez}

Profesora asociada de Didáctica de la Lengua en la Facultad de Educación de la Universidad de Murcia (España) y profesora de Lengua y Literatura en el IES Manuel Tárraga Escribano. Ha trabajado durante más de 15 años como redactora y creativa publicitaria. Sus trabajos se encuadran en el campo del análisis crítico de los discursos publicitario y mediático. Es autora, entre otros trabajos, de "JASP, rebeldes y espontáneos. El discurso publicitario juvenil como ejemplo de doble vínculo" (1996), Cultura y publicidad en el nuevo capitalismo globalizado (2001), "Cyborgs, forenses y la axila de Sanex. El cuerpo en la sociedad mediática" (2003), "Del uniforme del capitán América al azul desnudo del Dr. Manhattan. Ascenso y caída del superhéroe como principio de construcción identitaria" (2004) o "Cuando IO soy la marca. La solidaridad como construcción publicitaria” (2005).

mjoselucerga@gmail.com 